\title{
Organizational climate, organizational citizenship behaviour and turnover intention: Evidence
} from Jordan

\author{
Mohannad Obeid Al Shbail ${ }^{a^{*}}$ and Awn Metlib Abdulla Al Shbail a
}

${ }^{a}$ Al al-Bayt University, Jordan

C H R O N I C L E

\section{Article history:}

Received: June 26, 2020

Received in revised format:

June 302020

Accepted: July 26, 2020

Available online:

July 26, 2020

Keywords:

Organizational climate

$O C B$

Turnover intention

Internal auditors

Jordan

\begin{abstract}
A B S T R A C T
The present paper attempts to analyse the effect of organizational climate on organizational citizenship behaviour (OCB), as well as the effect of OCB on turnover intention. Data on organizational climate, $\mathrm{OCB}$ and turnover intention were obtained from a sample of 78 internal auditors of Jordanian private universities. Hypotheses were proposed and were tested using PLS-SEM, and the outcomes demonstrate the positive linkage between organizational climate and OCB. Meanwhile, OCB and turnover intention were found to have inverse linkage. Strong organizational climate should be created in Jordanian private universities since it improves and predicts OCB. OCB will in turn cause turnover intention to decrease among internal auditors. With the use of PLS-SEM method, this study adds to the extant literature.
\end{abstract}

\section{Introduction}

It is common for organisations to desire employees who are collaborative, proactive, and demonstrate high commitment highperformance standards. Such employees are effective and efficient, and they would contribute to the achievement of organizational excellence. Individual employee behaviour is vital in the achievement of such excellence, and appropriately, Organizational Citizenship Behaviours (OCBs) encompass a distinctive work behaviour type, expressed as the behaviours of individuals that are deemed constructive to the organization. Notably, these behaviours appear to be discretionary, and are not acknowledged by the by the formal reward system either directly or explicitly. Expressed differently, the behaviours are motivated by personal choice, and thus, their absences usually will not bring punishment. It is believed that OCB significantly affects the effectiveness and efficiency of work teams and organizations. For this reason, Ummah and Athambawa (2018) reported that OCB contributes to the organization's overall productivity. Bateman and Organ (1983) perceived OCB as an added-role behaviour denoting the presentation of constructive propositions leading to organisational development as well as the efforts made to altruistically assist others. Rotundo and Sackett (2002) regard OCB as an essential constituent of job performance. However, OCB goes beyond the conventional measures of job performance; it manifests a behaviour type which refers to the unexpected constructive contributions of employees. The past three decades have seen OCB being regarded as a key construct within the domains of accounting, management, as well as psychology. Indeed, the relevant literature has shown significant amount of studies exploring OCB (e.g., Bateman \& Organ, 1983; Boiral et al., 2015; Hammer et al., 2016; Niehoff \& Moorman, 1993; Organ \& Ryan, 1995; Pitaloka \& Sofia, 2014; Podsakoff et al., 2000; Teimouri et al., 2015), implying its importance, particularly within the domains of service. OCB has been implemented in many organizations including restaurants and healthcare facilities. However, in the context of universities, (Farooqui, 2012) mentioned the neglect of this concept. 
Organ (1988) regarded OCB as a critical factor contributing to the continued existence of an organisation. It is therefore important to have the awareness of the variables which significantly and positively assist in the formation of this sought-after behaviour inside the organisation. As found in various studies (e.g., Alotaibi, 2001; Bateman \& Organ, 1983; Chahal \& Mehta, 2010; Darto et al., 2015; Foote \& Li-Ping Tang, 2008; Jahangir et al., 2004; Khokhar \& Zia-ur-Rehman, 2017; Organ, 1990, 1997; Organ \& Lingl, 1995; Organ \& Moorman, 1993; Penner et al., 1997; Shahin et al., 2014; Tang \& Ibrahim, 1998), in an organization, the behaviour of citizenship is impacted by variables including employee satisfaction, leadership, leadership behaviour, motivation, organisational commitment, organisational justice, organizational climate, organizational culture, as well as personality.

As explained in Denison (1996), organizational climate encompasses a lasting quality experienced by employees, affecting their behaviour; this can be regarded as a portion of the organization's environment. Relevantly in Hughes et al. (2008), supportive climate encompasses the degree of perceived cooperation, coordination and support of direct supervisor which impact the organizational commitment of employees in a constructive manner. In fact, supportive climate has been found to have strong linkage with outcomes including innovation, employee diligence, employee performance, organizational commitment, and job satisfaction (Chory \& Hubbell, 2008; Huang et al., 2010; Lambert et al., 2012). Supportive climate has also been linked to the decrease of problems including hostility, interpersonal aggression, employee burnout, obstructionism, absenteeism and deception (Chory \& Hubbell, 2008; Huang et al., 2010; Lambert et al., 2012). Furthermore, climate has a strong linkage to citizenship behaviour (Qadeer \& Jaffery, 2014). Hence, organizational climate is examined as OCB predictor in the present study.

The reasons underpinning OCB are sufficiently understood. Nonetheless, the impacts of OCB on organizational effectiveness or some other measures of organizational effectiveness (e.g., employee turnover) have not been sufficiently examined, creating an empirical gap to the OCB literature. Also, from the many studies that identify OCB's impacting factors, only a handful that actually examined if these human behaviours indeed contribute to the quitting intention. Furthermore, the presently available literature shows the dearth of studies that addressed the impacts of OCB on variables such as employee turnover. In fact, only a handful has examined the linkage between OCB and employee turnover (e.g., Chen et al., 1998). As such, not much generalization can be made to the issue at hand, and this also calls for more probe and validation of the research findings.

According to Angle and Perry (1981), turnover is among the criteria for organizational accomplishment or a substitute of organizational effectiveness, and for this reason, turnover outcome is worth the scrutiny. Turnover encompasses a permanent elimination of an employee from the organization, and the elimination can be voluntary or involuntary. As indicated in Boshoff and Mels (2000), the most injurious to the organization is voluntary turnover because this type of turnover generally takes the organization by surprise. As proven by a significant number of findings, employee turnover impacts organization performance. As indicated in Koys (2003), turnover causes the costs associated with separation, replacement, and training to escalate. The factors that contribute to turnover have been explored by a lot of studies (Shaw et al., 1998). However, most of these studies were concentrating mostly on antecedents such as demographic factors, cognitive process, commitment, and job satisfaction, while the role of behavioural antecedents has not been adequately examined.

In the context of internal auditors, their retention is of an exceptional concern because as indicated in Ahmed and Shil (2015), internal auditors add value to the decisions made by management. Accordingly, the notion of value-added internal audit has been directly linked to the effectiveness of internal audit (Lenz \& Hahn, 2015). Furthermore, as indicated in Ahmed and Shil (2015), internal auditors give advices on the usefulness and implementation of internal controls. Chambers (2015) further added that internal audit assists organization in accomplishing its organizational missions and visions while also making available a procedure for the assessment of risk management, control, as well as the processes of governance. Accordingly, the merit of an internal audit function has been acknowledged by the New York Stock Exchange, and due to this, Chambers (2015) reported that all listed companies are required to have internal audit function. In this regard, a successful company without an internal audit function should be a signal for warning.

For any organization, internal auditors play a crucial role, and for this reason, it is important for an organization to have the awareness of the factors impacting OCB of internal auditors to assure its financial success. Also, internal auditors work in the organization so that they could monitor and assess how well risks are being handled, the business is being run, as well as how well the internal processes are functioning. Hence, internal auditors are obliged to perform optimally to fulfil the needs of the organization. On the other hand, organization is obliged to have the appropriate strategies for retaining its employees, in this context, the internal auditors, and achieve better performance. Hence, this study attempts to find out how the organizational climate as antecedent leads to OCB of internal auditors, and how OCB affect the internal auditors' turnover intention.

In the context of Jordanian private universities, the establishment of OCB among employees is now highly crucial for the improvement of competitiveness of these universities. As can be observed in the OCB literature, a gap is present relating to the studies that explored this variable in the country's sector of higher education. In fact, most past works on OCB were carried out by industrial organizational and occupational psychologists. Hence, having the factors impacting OCB among university internal auditors examined in this study, constructive suggestions are hoped to be presented to the management in higher educational institutions. This would allow these institutions to construct the strategies which could assist them in bringing in and keeping their employees in the long term. 


\section{Theoretical framework and hypotheses development}

\subsection{Organizational climate and $O C B$}

Organizational climate has been evidenced as a factor affecting the behaviour of members of organization (Alipour, 2011; Öz et al., 2010). Essentially, organizational climate encompasses a group containing quantifiable criteria within the working atmosphere which is understood, directly or indirectly, by those who act in such a situation, and it impacts both their motivation and behaviour. Hence, the scrutiny of organizational climate, the determination of the type, and the attempt at improving it, can improve other organizational variables as well. Meanwhile, Podsakoff et al. (2000) mentioned that organizational citizenship behaviour, which is a non-compulsory behaviour, can be more strongly affected by numerous factors associated with attitudes as well as personalities. Hence, by taking into account the effect of organizational climate on the behaviour of employees, organizations should always pursue the identification, change, and improvement of organizational climate. This will affect the employees' personal behaviour while also easing the accomplishment of organizational goals. As today's environment is highly competitive, organizational effectiveness and survival are impacted by the attitudes and behaviours of employees, increasing the importance of organizational climate among scholars of organizational behaviour. Organizational climate has in fact been examined in numerous organizational contexts, and it has been linked to several results relating to individual, group, and organization. In specific, in past studies (e.g., Ahmad et al., 2012; Bellou \& Andronikidis, 2009; Dickson et al., 2006; Rahimic, 2013; Zhang \& Liu, 2010), organizational climate has been linked to variables including productivity, job satisfaction, employee performance, organizational effectiveness, organizational justice, organizational commitment, work motivation, organizational alienation, predisposition to leave, as well as anxiety. However, organizational climate has been suggested to promote favorable behaviours in organizations. These favourable behaviours include OCB, as well as creative, proactive, and innovative behaviour (Lin \& Lin, 2011; Moghimi \& Subramaniam, 2013; Patterson et al., 2004; Peterson, 2002; Randhawa \& Kaur, 2015). Considering these findings, the hypothesis below is presented;

H1: There is a positive relationship between the organizational climate and the levels of OCB.

\section{$2.2 O C B$ and turnover intention}

OCB is a concept that has been debated by scholars. For instance, Danayifar et al. (2010) viewed OCB as the reflection of how employees voluntarily act towards their work and the act is clearly not part of their job descriptions. There are employees who would do good deeds willingly, while others would not. In this regard, OCB can be illustrated as a performance of certain good deeds towards the organization with no anticipation of retribution of any kind from the involved third party. Relevantly, Khalid et al. (2013) describe OCB as voluntary and discretionary unexpected behaviours for assisting the peers in achieving success. Also, OCB causes the work culture of cooperation to increase, and it also incidentally forms an entity in organization classified under unprompted behaviour. Hence, OCB impacts the image and reputation of the organization. The linkage between OCB and turnover intention is currently a subject of interest among scholars (Chen, 2005; Chen et al., 1998; Mossholder et al., 2005; Paillé, 2013; Saraih et al., 2017). In Chen et al. (1998; 2005), the authors found behavioural antecedents as crucial predictors of turnover intention and actual turnover. Accordingly, OCB can justifiably be employed in predicting turnover intention. Several past works (e.g., Chen et al., 1998; Chen, 2005; Podsakoff et al., 2009) have also scrutinized the linkage between OCB and turnover intention. Furthermore, Chen et al. (1998) found that the intensities of OCB denote the true willingness and inclination of employees, how much involvement they would like to have with their organization, or how much they want to steer clear from the organization. Here, the key argument is that lower OCB level denotes stronger reluctance signal of the employee in being part of the organization, which can be translated into higher likelihood of employees to leave the organization. The linkage between OCB and turnover intention has been examined in past studies. Oren et al. (2012) for instance, reported an adverse linkage between both variables, and regard OCB as a behaviour that is advantageous to the organization. On the other hand, the authors classed turnover intention under a withdrawal reaction in a non-favourable manner towards the organization. Also, employees with high level of OCB are less inclined to be eliminated from their present workplace as opposed to those with low level of OCB (Sharma et al., 2010). Interestingly, in the context of hotel industry employees, Khalid et al. (2009) reported a positive linkage of OCB to turnover intention. Notably, low intentions of employees to leave the organization are signified by a high level of OCB, and according to Khalid et al. (2013), it constantly fashioned other constructive attitudes and behaviour at workplace. Considering these findings, the hypothesis below is presented;

H2: There is an inverse relationship between the level of $O C B$ and turnover intention.

\section{Methodology}

\subsection{Research Respondents}

Internal auditors employed at Jordanian private universities were chosen as respondents in this study. As at 2019, Jordan has 20 private universities (Ministry of Higher Education \& Scientific Research, 2019) and these universities were chosen as this study's population. The sample determination in this study was based on Hair et al. (2011). In particular, the authors suggested selecting sample size of at least 10-20 times more than the required variables in order that it will be appropriately sufficient for the analysis. As such, a total of 130 respondents were chosen, and questionnaire was the method employed for data gathering. The 130 sets of questionnaires were personally handed to the respondents. This is to assure that sufficient amount of responses would be obtained. Accordingly, this study obtained $74 \%$ response rate (96 returned questionnaires), but due to 
incompletion of 18 sets of the returned questionnaires, only 78 sets of questionnaires underwent further analysis. The study period started in July 2019 and ended in September, 2019. From the responses obtained, most respondents were aged 30 and below (67\%), were male (88.3\%), were married (53\%), were holder of Master's degree (12\%), and had been employed as internal auditor for $1-3$ years $(71 \%)$.

\subsection{Measuring Instrument}

Organizational climate: This construct was measured using the modified scales of Kao (2015, 2017). In particular, Kao's (2015) scales were grounded upon the Organizational Climate Questionnaire (LSOCQ) created by Litwin and Stringer (1968). In the questionnaire, this construct is represented by 9 items as detailed as follows: interpersonal relationship (4 items), structure climate (3 items), and responsibility climate (2 items) (Kao, 2015). Cronbach's Alpha was used to determine the instrument's reliability and, in this study, the value obtained was 0.834 .

Organizational Citizenship Behaviour: This construct was measured using the modified scales of "Organizational Citizenship Behaviour (Individual)" by Lee and Allen (2002), which contains a statement leading to interpersonal facilitation (Van Scotter \& Motowidlo, 1996), interpersonal harmony (Farh et al., 1997; Okeke \& Nwankpa, 2018) and interpersonal helping (Graham, 1991). In responding to the items of this construct, the participants were asked to denote how often they would be engaged in the identified behaviours. For the responses, the construct employs the 7-point scale $(1=$ never, $7=$ always). Cronbach's Alpha was used to determine the instrument's reliability and, in this study, the value obtained was 0.799 .

Turnover Intention: This construct was measured using 6 items obtained from Bothma and Roodt (2013). These items particularly evaluate the intent of the respondents to leave his/her current job. This measure has been previously employed in the literature relating to auditors and turnover (e.g., Al-Shbiel et al., 2018). For the responses, the construct employs the 7-point Likert scale. For the items of this construct, the previously achieved Cronbach's alpha was 0.911 , and according to Bothma and Roodt (2013), the obtained value denotes that the internal reliability and construct validity of the items are acceptable.

\subsection{Analytical method}

Partial least squares (PLS) structural equation modeling (SEM) technique run with SmartPLS version 3.0 was used in this study for data analysis. As a SEM method, PLS assists in the analysis of the models of structural measurement and the associated paths. This method also offers factor loadings that are identical to the principal of component analysis (see Sosik et al., 2009). Hence, the use of PLS enables the examination of the research model in terms of its validity and the analysis of the empirical model in regards to the hypothesized relationships along with their significance. As mentioned in past studies (e.g., Hair et al., 2013), the application of PLS is advantageous over other possible methods related to structural modeling. To begin with, the use of PLS enables the scrutiny of variables that have non-normal distributions (e.g., measures of turnover intention). Another advantage is that, for estimations of path model, PLS appears to work. It is also appropriate for small sample sizes in relation to the complexity of the research model $(n=78)$. Also, PLS is appropriate for exploratory studies such as this study. In the context of this study, previous knowledge regarding the relationships between OCB and turnover intention in the domain of auditing is very little.

\section{Results}

\subsection{Measurement model}

Construct reliability is affirmed by checking the item loadings and values of composite reliability. In particular, for the reliability of individual item, the loadings are checked. In general, loadings should at least 0.7 (Hair et al., 2017). Still, Hulland (1999) mentioned the possibility of some items in an estimated model to have lower loadings, particularly for newly constructed scales or the presently available scales that were transferred to a different context. Meanwhile, Hair et al. (2017) stated that loadings between 0.40 and 0.70 would only cause removal to the given items if their removal would increase the composite reliability or average variance extracted (AVE). Hence, 2 items from organizational climate, 2 from OCB, and 1 from turnover intention were eliminated as their loadings were lower than 0.4 and were also suitable to be eliminated. The elimination increased the composite reliability and AVE values. Meanwhile, the rest of the items were retained. In the use of PLS-SEM, Hair et al. (2017) suggested the use of the composite reliability score for construct reliability, even though the more common measure of internal consistency is Cronbach's alpha. As opposed to Cronbach's alpha, composite reliability does not presuppose the equal reliability of all indicators. Cronbach's alpha also demonstrates sensitivity to the number of items within the scale (Hair et al., 2011; Hair et al., 2017). Based on the outcomes shown in Table 1, for all latent variables, the composite reliability appears to be higher the commended threshold of 0.7 . As for this study's convergent validity measure, it employs AVE, which should be higher than 0.5 as suggested in Hair et al. (2017). In this study, the lowest AVE is 0.63 , implying the fulfilment of the requirement for all constructs. In terms of the internal consistency of each construct, it is deemed sufficient. As assurance of discriminant validity, each construct also must share more variance with its measures as opposed to with any other constructs, and this is signified by a higher square root of the AVE for each construct in comparison to its correlations with other constructs (Fornell \& Larcker, 1981; Hair et al., 2017). Furthermore, it is required that the square root of the AVE is no less than 0.7 (Chin, 1998). In this study, all the constructs met these criteria (see Table 2), implying the existence of discriminant validity. 
Table 1

Measurement model

\begin{tabular}{|c|c|c|c|c|c|}
\hline Construct & Items & Loadings & CR & C. Alpha & AVE \\
\hline \multirow{7}{*}{ Organizational Climate } & OC1 & 0.703 & \multirow{7}{*}{0.835} & \multirow{7}{*}{0.834} & \multirow{7}{*}{0.633} \\
\hline & OC3 & 0.724 & & & \\
\hline & OC4 & 0.767 & & & \\
\hline & OC5 & 0.813 & & & \\
\hline & OC6 & 0.921 & & & \\
\hline & OC7 & 0.775 & & & \\
\hline & OC9 & 0.863 & & & \\
\hline \multirow{10}{*}{ Organizational Citizenship Behaviour } & OCB1 & 0.875 & \multirow{10}{*}{0.804} & \multirow{10}{*}{0.799} & \multirow{10}{*}{0.671} \\
\hline & OCB2 & 0.933 & & & \\
\hline & OCB3 & 0.778 & & & \\
\hline & OCB5 & 0.797 & & & \\
\hline & OCB7 & 0.798 & & & \\
\hline & OCB8 & 0.938 & & & \\
\hline & OCB9 & 0.788 & & & \\
\hline & OCB10 & 0.811 & & & \\
\hline & OCB11 & 0.736 & & & \\
\hline & OCB12 & 0.764 & & & \\
\hline \multirow{5}{*}{ Turnover Intention } & TI1 & 0.911 & \multirow{5}{*}{0.916} & \multirow{5}{*}{0.911} & \multirow{5}{*}{0.741} \\
\hline & TI3 & 0.737 & & & \\
\hline & TI4 & 0.902 & & & \\
\hline & TI5 & 0.847 & & & \\
\hline & TI6 & 0.722 & & & \\
\hline
\end{tabular}

Table 2

Discriminant validity

\begin{tabular}{lcc}
\hline & Organizational Climate & Organizational Citizenship Behaviour \\
\hline Organizational Climate & $\mathbf{0 . 7 9 5}$ & \\
Organizational Citizenship Behaviour & 0.542 & $\mathbf{0 . 8 1 9}$ \\
Turnover Intention & 0.694 & 0.528 \\
\hline
\end{tabular}

\subsection{Structural model}

In this study, the structural model is evaluated using the values of $\mathrm{R}^{2}$ of the dependent variable as follows: 0.38 for OCB and 0.49 for turnover intention. These values are all greater than the commonly tolerated thresholds mentioned in Falk and Miller (1992), Chin (1998) and Hair et al. (2011). Moreover, these values appear to correspond with the values mentioned in PLS research in accounting and auditing (e.g., Al Shbail et al., 2018a, 2018b; Obeid et al., 2017). In this study, the significance of the coefficients is decided based on 5000 bootstrap samples (Hair et al., 2011). Accordingly, the hypotheses testing results are displayed in Table 3 below.

Table 3

Structural model results

\begin{tabular}{|c|c|c|c|}
\hline \multirow{2}{*}{ Structural path } & \multirow{2}{*}{ Path coefficient and (T-Statistics) } & Percentile $95 \%$ confidence intervals & \multirow{2}{*}{ Conclusion } \\
\hline & & $95 \% \mathrm{UL}$ & \\
\hline $\mathrm{H} 1: \mathrm{OC} \rightarrow \mathrm{OCB}$ & $0.385(4.262)^{*}$ & $(0.103 ; 0.498)$ Sig & Supported \\
\hline $\mathrm{H} 2: \mathrm{OCB} \rightarrow \mathrm{TI}$ & $-0.288(3.896) *$ & $(-0.433 ;-0.046)$ Sig & Supported \\
\hline
\end{tabular}

Note: $*|t| \geq 3.09$ at $\mathrm{p} 0.001$ level (based on $\mathrm{t}(4999)$, one tailed test); $\mathrm{OC}=$ Organizational Climate, $\mathrm{OCB}=$ Organizational Citizenship Behaviour, $\mathrm{TI}=\mathrm{Turnover}$ Intention.

Consistent with hypothesis $\mathrm{H} 1$ established in this study, organizational climate imparts a positive impact on OCB ( $\beta=0.385$, $\mathrm{p}<0.05)$. This result is also in agreement with the past models of research which posit organizational climate as OCB antecedent. Also, as posited in H2, OCB appears to have a significant negative impact on the turnover intention of internal auditors $(\beta=-0.288, p<0.05)$.

\section{Conclusions}

Among internal auditors, the deterioration rate is high, and it is now a global issue, while also causing great challenges for business leaders. Turnover among internal auditors has both direct and indirect costs, implying high cost of turnover to the organization. As found in this study, OCB of high level was the general reason why internal auditors remain in their job. In addition, organizational climate appears to be the OCB antecedent. This study further plays a significant role in the evaluation of the factors known to increase OCB among internal auditors. As such, in the context of private universities, internal auditor empowerment should be improved by way of work environment. Systematic assessment of work environment should be made for monitoring as well as evaluating the physical work condition, the communication climate, as well as how appropriate the rules and procedures correspond with the strategies of the organization. Hence, the internal auditor's psychological empowerment and performance could be enhanced. Furthermore, competence-based performance appraisals should be implemented, and employees should have the awareness regarding their roles, competences, as well as the performance output expected. As proven in this study, with OCB fostered, the university will have employees that are loyal, and this will decrease the problem 
of turnover. At the same time, the quality of work displayed by the employees will increase organizational performance and competitive advantage. Nonetheless, several limitations to this study should be pointed out as well. Firstly, this study is a cross-sectional study since conducting longitudinal studies on this subject is difficult. Another limitation is the uniqueness of the sample which brings to the question of whether public universities have similar characteristics. Notably, the proposed model may be tested in other economic professions and sectors as well. The measurement of turnover using future intentions is another limitation in this study. It should be noted that even though the scale employed in this study has been employed in many past works, it is essentially a subjective behaviour measurement. As a final point, the model proposed in this work does not consider the linkage between organizational climate and the turnover intention of internal auditors.

\section{References}

Ahmad, Z., Ali, L., \& Ahmad, N. (2012). Organizational climate: A study of pharmaceutical industry in Pakistan. African Journal of Business Management, 6(49), 11880-11886.

Ahmed, M., \& Shil, S. (2015). Protecting existing and prospective investors and the role of internal auditors. Independent Business Review, 6(2), 26-51.

Al-Shbiel, S. O., Ahmad, M. A., Al-Shbail, A. M., Al-Mawali, H., \& Al-Shbail, M. O. (2018). The mediating role of work engagement in the relationship between organizational justice and junior accountants' turnover intentions. Academy of Accounting \& Financial Studies Journal, 22(1), 1-23.

Al Shbail, M., Salleh, Z., \& Mohd Nor, M. (2018a). Antecedents of burnout and its relationship to internal audit quality. Business and Economic Horizons, 14(4), 789-817.

Al Shbail, M., Salleh, Z., \& Mohd Nor, M. (2018b). The effect of ethical tension and time pressure on job burnout and premature sign-off. Journal of Business and Retail Management Research, 12(4), 43-53.

Alipour, F. H. (2011). The relationship between organizational climate and communication skills of managers of the Iranian physical education organization. Procedia-Social and Behavioral Sciences, 30, 421-428.

Alotaibi, A. G. (2001). Antecedents of organizational citizenship behavior: A study of public personnel in Kuwait. Public Personnel Management, 30(3), 363-376.

Angle, H. L., \& Perry, J. L. (1981). An empirical assessment of organizational commitment and organizational effectiveness. Administrative science quarterly, 26(1), 1-14.

Bateman, T. S., \& Organ, D. W. (1983). Job satisfaction and the good soldier: The relationship between affect and employee "citizenship". Academy of Management Journal, 26(4), 587-595.

Bellou, V., \& Andronikidis, A. I. (2009). Examining organizational climate in Greek hotels from a service quality perspective. International Journal of Contemporary Hospitality Management, 21(3), 294-307.

Boiral, O., Talbot, D., \& Paillé, P. (2015). Leading by example: A model of organizational citizenship behavior for the environment. Business Strategy and the Environment, 24(6), 532-550.

Boshoff, C., \& Mels, G. (2000). The impact of multiple commitments on intentions to resign: An empirical assessment. British Journal of Management, 11(3), 255-272.

Bothma, C. F., \& Roodt, G. (2013). The validation of the turnover intention scale. SA Journal of Human Resource Management, 11(1), 1-12.

Chahal, H., \& Mehta, S. (2010). Antecedents and consequences of organisational citizenship behaviour (OCB): A conceptual framework in reference to health care sector. Journal of Services Research, 10(2), 25-44.

Chambers, R. (2015). No internal audit function? Investors beware. Internal Auditor. Retrieved from https://iaonline.theiia.org/blogs/chambers/2015/no internal-auditfunction-investors-beware. Accessed Aug, 28, 2018.

Chen, X.-P. (2005). Organizational citizenship behavior: A predictor of employee voluntary turnover. In D. L. Turnipseed (Ed.), Handbook of organizational citizenship behavior (pp. 435-454). New York: Nova Science.

Chen, X.-P., Hui, C., \& Sego, D. J. (1998). The role of organizational citizenship behavior in turnover: Conceptualization and preliminary tests of key hypotheses. Journal of Applied Psychology, 83(6), 922-931.

Chin, W. W. (1998). The partial least squares approach to structural equation modeling. Modern Methods for Business Research, 295(2), 295-336.

Chory, R. M., \& Hubbell, A. P. (2008). Organizational justice and managerial trust as predictors of antisocial employee responses. Communication Quarterly, 56(4), 357-375.

Danayifar, H., Ebrahimi, A., \& Kashi, K. (2010). Good soldiers' perceptions of organizational politics: Understanding the relation between organizational citizenship behaviours and perceptions of organizational politics: evidence from Iran. European Journal of Economics, Finance and Administrative Sciences, 18, 146-162.

Darto, M., Djoko, S., Sukiano, S., \& Sugeng, H. (2015). The Effect of Transformational Leadership, Religiosity, Job Satisfaction, and Organizational Culture on Organizational Citizenship Behavior and Employee Performance in the Regional Offices of National Institute of Public Administration, Republic of Indonesia. European Journal of Business and Management, 7(23), 205219.

Denison, D. R. (1996). What is the difference between organizational culture and organizational climate? A native's point of view on a decade of paradigm wars. Academy of management Review, 21(3), 619-654.

Dickson, M. W., Resick, C. J., \& Hanges, P. J. (2006). When organizational climate is unambiguous, it is also strong. Journal of Applied Psychology, 91(2), 351-364.

Falk, R. F., \& Miller, N. B. (1992). A primer for soft modeling. Akron, OH: University of Akron Press.

Farh, J.-L., Earley, P. C., \& Lin, S.-C. (1997). Impetus for action: A cultural analysis of justice and organizational citizenship behavior in Chinese society. Administrative Science Quarterly, 42(3), 421-444.

Farooqui, M. R. (2012). Measuring organizational citizenship behavior (OCB) as a consequence of organizational climate (OC). Asian Journal of Business Management, 4(3), 294-302. 
Foote, D. A., \& Li-Ping Tang, T. (2008). Job satisfaction and organizational citizenship behavior (OCB) does team commitment make a difference in self-directed teams? Management Decision, 46(6), 933-947.

Fornell, C., \& Larcker, D. F. (1981). Structural equation models with unobservable variables and measurement error: Algebra and statistics. Journal of Marketing Research, 18(3), 382-388.

Graham, J. W. (1991). An essay on organizational citizenship behavior. Employee Responsibilities and Rights Journal, 4(4), 249270.

Hair, Ringle, M., \& Sarstedt, M. (2011). PLS-SEM: Indeed a silver bullet. Journal of Marketing theory and Practice, 19(2), 139152.

Hair, J., F, Hult, G., Ringle, C., \& Sarstedt, M. (2017). A primer on partial least squares structural equation modeling (PLS-SEM) $\left(2^{\text {nd }}\right.$ ed). Thousand Oaks, CA: Sage.

Hair, J., Ringle, C., \& Sarstedt, M. (2013). Editorial-partial least squares structural equation modeling: Rigorous applications, better results and higher acceptance. Long Range Planning, 46(1-2), 1-12.

Hair, J. F., Ringle, C. M., \& Sarstedt, M. (2011). PLS-SEM: indeed a silver bullet. Journal of Marketing Theory and Practice, 19(2), 137-149.

Hammer, L. B., Johnson, R. C., Crain, T. L., Bodner, T., Kossek, E. E., Davis, K. D., . . Chosewood, L. C. (2016). Intervention effects on safety compliance and citizenship behaviors: Evidence from the work, family, and health study. Journal of Applied Psychology, 101(2), 190-208.

Huang, X., Iun, J., Liu, A., \& Gong, Y. (2010). Does participative leadership enhance work performance by inducing empowerment or trust? The differential effects on managerial and non-managerial subordinates. Journal of Organizational Behavior, 31(1), $122-143$.

Hughes, L. W., Avey, J. B., \& Norman, S. M. (2008). A study of supportive climate, trust, engagement and organizational commitment. Journal of Business \& Leadership: Research, Practice, and Teaching, 4(2), 51-59.

Hulland, J. (1999). Use of partial least squares (PLS) in strategic management research: A review of four recent studies. Strategic Management Journal, 20(2), 195-204.

Jahangir, N., Akbar, M. M., \& Haq, M. (2004). Organizational citizenship behavior: Its nature and antecedents. Journal of BRAC University, 1(2), 75-85.

Kao, R.-H. (2015). A study on the relationship between transformational leadership and organizational climate: Using HLM to Analyze Context effects of Police Organization. Global Advanced Research Journal of Management and Business Studies, 4(3), 087-115.

Kao, R.-H. (2017). The relationship between work characteristics and change-oriented organizational citizenship behavior: A multilevel study on transformational leadership and organizational climate in immigration workers. Personnel Review, 46(8), 18901914.

Khalid, S. A., Jusoff, H. K., Ali, H., Ismail, M., Kassim, K. M., \& Rahman, N. A. (2009). Gender as a moderator of the relationship between OCB and turnover intention. Asian Social Science, 5(6), 108-117.

Khalid, S. A., Nor, M. N. M., Ismail, M., \& Razali, M. F. M. (2013). Organizational citizenship and generation Y turnover intention. International Journal of Academic Research in Economics and Management Sciences, 2(4), 132-141.

Khokhar, A. M., \& Zia-ur-Rehman, M. (2017). Linking ethical leadership to employees' performance: Mediating role of organizational citizenship behavior and counterproductive work behavior. Pakistan Journal of Commerce \& Social Sciences, 11(1), 321350.

Lambert, E. G., Hogan, N. L., Barton-Bellessa, S. M., \& Jiang, S. (2012). Examining the relationship between supervisor and management trust and job burnout among correctional staff. Criminal Justice and Behavior, 39(7), 938-957.

Lee, K., \& Allen, N. J. (2002). Organizational citizenship behavior and workplace deviance: The role of affect and cognitions. Journal of Applied Psychology, 87(1), 131-142.

Lenz, R., \& Hahn, U. (2015). A synthesis of empirical internal audit effectiveness literature pointing to new research opportunities. Managerial Auditing Journal, 30(1), 5-33.

Lin, J. S.-J., \& Lin, S.-C. (2011). Moderating effect of organizational climate on the relationship of organizational support and service-oriented organizational citizenship behaviors. African Journal of Business Management, 5(2), 582-595.

Litwin, G. H., \& Stringer, R. A. (1968). Motivation and organizational climate. Cambridge, MA: Harvard Business School, Division of Research.

Moghimi, S., \& Subramaniam, I. D. (2013). Employees' creative behavior: The role of organizational climate in Malaysian SMEs. International Journal of Business and Management, 8(5), 1-12.

Mossholder, K. W., Settoon, R. P., \& Henagan, S. C. (2005). A relational perspective on turnover: Examining structural, attitudinal, and behavioral predictors. Academy of Management Journal, 48(4), 607-618.

Niehoff, B. P., \& Moorman, R. H. (1993). Justice as a mediator of the relationship between methods of monitoring and organizational citizenship behavior. Academy of Management Journal, 36(3), 527-556.

Obeid, M., Salleh, Z., \& Mohd Nor, M. (2017). The Mediating Effect of Job Satisfaction on The Relationship Between Personality Traits and Premature Sign-off. Academy of Accounting and Financial Studies Journal, 21(2), 1-17.

Okeke, R., \& Nwankpa, L. (2018). Financial accountability, ethical issues and organizational citizenship behavior in fragile economic systems: The case of the Nigerian economy. Accounting, 4(4), 161-170.

Oren, L., Tziner, A., Sharoni, G., Amor, I., \& Alon, P. (2012). Relations between leader-subordinate personality similarity and job attitudes. Journal of Managerial Psychology, 27(5), 479-496.

Organ, D. W. (1988). Organizational citizenship behavior: The good soldier syndrome. Lexington, MA: Lexington Books.

Organ, D. W. (1990). The motivational basis of organizational citizenship behavior. Research in Organizational Behavior, 12(1), 43-72.

Organ, D. W. (1997). Organizational citizenship behavior: It's construct clean-up time. Human Performance, 10(2), 85-97. 
Organ, D. W., \& Lingl, A. (1995). Personality, satisfaction, and organizational citizenship behavior. The Journal of Social Psychology, 135(3), 339-350.

Organ, D. W., \& Moorman, R. H. (1993). Fairness and organizational citizenship behavior: What are the connections? Social Justice Research, 6(1), 5-18.

Organ, D. W., \& Ryan, K. (1995). A meta-analytic review of attitudinal and dispositional predictors of organizational citizenship behavior. Personnel Psychology, 48(4), 775-802.

Öz, B., Özkan, T., \& Lajunen, T. (2010). An investigation of the relationship between organizational climate and professional drivers' driver behaviours. Safety Science, 48(10), 1484-1489.

Paillé, P. (2013). Organizational citizenship behaviour and employee retention: how important are turnover cognitions? The International Journal of Human Resource Management, 24(4), 768-790.

Patterson, M., Warr, P., \& West, M. (2004). Organizational climate and company productivity: The role of employee affect and employee level. Journal of Occupational and Organizational Psychology, 77(2), 193-216.

Penner, L. A., Midili, A. R., \& Kegelmeyer, J. (1997). Beyond job attitudes: A personality and social psychology perspective on the causes of organizational citizenship behavior. Human Performance, 10(2), 111-131.

Peterson, D. K. (2002). Deviant workplace behavior and the organization's ethical climate. Journal of Business and Psychology, $17(1), 47-61$.

Pitaloka, E., \& Sofia, I. P. (2014). The effect of work environment, job satisfaction, organization commitment on OCB of internal auditors. International Journal of Business, Economics and Law, 5(2), 10-18.

Podsakoff, N. P., Whiting, S. W., Podsakoff, P. M., \& Blume, B. D. (2009). Individual-and organizational-level consequences of organizational citizenship behaviors: A meta-analysis. Journal of Applied Psychology, 94(1), 122-141.

Podsakoff, P. M., MacKenzie, S. B., Paine, J. B., \& Bachrach, D. G. (2000). Organizational citizenship behaviors: A critical review of the theoretical and empirical literature and suggestions for future research. Journal of Management, 26(3), 513-563.

Qadeer, F., \& Jaffery, H. (2014). Mediation of psychological capital between organizational climate and organizational citizenship behavior. Pakistan Journal of Commerce and Social Sciences, 8(2), 453- 470.

Rahimic, Z. (2013). Influence of organizational climate on job satisfaction in bosnia and herzegovina companies. International Business Research, 6(3), 129-139.

Randhawa, G., \& Kaur, K. (2015). An empirical assessment of impact of organizational climate on organizational citizenship behaviour. Paradigm, 19(1), 65-78.

Rotundo, M., \& Sackett, P. R. (2002). The relative importance of task, citizenship, and counterproductive performance to global ratings of job performance: A policy-capturing approach. Journal of Applied Psychology, 87(1), 66-80.

Saraih, U. N., Aris, A. Z. Z., Karim, K. M., Samah, I. H. A., Sa'aban, S., \& Mutalib, S. A. (2017). Relationships between Organizational Commitment, OCB, Organizational Justice and Turnover Intention: Evidence from Educational Institution in Malaysia. Review of Integrative Business and Economics Research, 6(2), 64-77.

Shahin, A., Shabani Naftchali, J., \& Khazaei Pool, J. (2014). Developing a model for the influence of perceived organizational climate on organizational citizenship behaviour and organizational performance based on balanced score card. International Journal of Productivity and Performance Management, 63(3), 290-307.

Sharma, J. P., Bajpai, N., \& Holani, U. (2010). Organizational citizenship behavior in public and private sector and its impact on job satisfaction: A comparative study in Indian perspective. International Journal of Business and Management, 6(1), 67-75.

Shaw, J. D., Delery, J. E., Jenkins Jr, G. D., \& Gupta, N. (1998). An organization-level analysis of voluntary and involuntary turnover. Academy of Management Journal, 41(5), 511-525.

Sosik, J. J., Kahai, S. S., \& Piovoso, M. J. (2009). Silver bullet or voodoo statistics? A primer for using the partial least squares data analytic technique in group and organization research. Group \& Organization Management, 34(1), 5-36.

Tang, T. L.-P., \& Ibrahim, A. H. S. (1998). Antecedents of organizational citizenship behavior revisited: Public personnel in the United States and in the Middle East. Public Personnel Management, 27(4), 529-550.

Teimouri, H., Dezhtaherian, M., \& Jenab, K. (2015). Examining the relationship between person-organization fit and organizational citizenship behavior: The case of an educational institution. Annals of Management Science, 4(1), 23-44.

Ummah, S., \& Athambawa, S. (2018). Organizational citizenship behavior and job satisfaction among non-academic employees of national universities in the Eastern province of Sri Lanka. American Journal of Economics and Business Management, 1(1), 7584.

Van Scotter, J. R., \& Motowidlo, S. J. (1996). Interpersonal facilitation and job dedication as separate facets of contextual performance. Journal of Applied Psychology, 81(5), 525-531.

Zhang, J., \& Liu, Y. (2010). Organizational climate and its effects on organizational variables: An empirical study. International Journal of Psychological Studies, 2(2), 189-201.

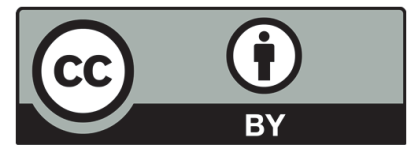

(C) 2020 by the authors; licensee Growing Science, Canada. This is an open access article distributed under the terms and conditions of the Creative Commons Attribution (CC-BY) license (http://creativecommons.org/licenses/by/4.0/). 